\title{
Clinical and microbiological profile of infectious keratitis in children
}

\author{
Patricia Chirinos-Saldaña', Victor Manuel Bautista de Lucio², Julio Cesar Hernandez-Camarena', Alejandro Navas', \\ Arturo Ramirez-Miranda', Lizet Vizuet-Garcia², Mariana Ortiz-Casas², Nadia Lopez-Espinosa², Carolina Gaona-Juarez², \\ Luis Antonio Bautista-Hernandez ${ }^{2}$ and Enrique $O$ Graue-Hernandez ${ }^{1 *}$
}

\begin{abstract}
Background: Infectious keratitis is a sight-threatening condition for children. The purpose of this study was to describe the clinical profile, risk factors and microbiological profile of infectious keratitis in children.

Methods: Retrospective review of clinical records of patients under 16 years of age with history of microbial keratitis seen at a tertiary referral center. Clinical characteristics, risk factors, visual and surgical outcomes as well as the microbiological profile are analyzed.

Results: Forty-one eyes of 41 patients. Mean age was 8.7 years. Time between the onset of symptoms and ophthalmological examination was 12.7 days. Predisposing factors were found in 78\%; ocular trauma was the most common (25\%). Visual acuity equal or worse than 20/200 at admission correlated positively with a poorer visual outcome, $\mathrm{p}=0.002$. Positivity of cultures was $34 \%$. Gram-positive bacteria were isolated in $78.5 \%$; Staphylococcus epidermidis (28.6\%) was the most common microorganism.
\end{abstract}

Conclusions: Our study emphasizes the importance of a prompt diagnosis and treatment of infectious corneal ulcers in children. Trauma and contact lenses were the main predisposing factors. Gram-positive organisms were isolated in the vast majority of cases and visual outcomes are usually poor.

Keywords: Paediatrics, Children, Drug-resistance, Microbial, Risk factors

\section{Background}

Worldwide, infectious corneal disease is an important cause of visual impairment and blindness, with reported annual incidence between 1.5 to 8 million [1], being more prevalent in developing countries. Although, infectious keratitis is an uncommon event in paediatric patients, amblyopia is of concern, since altered corneal transparency during infancy prevents normal neurophysiological development [2].

According to the World Health Organization (WHO), approximately 700,000 children annually develop corneal pathology that permanently affects their vision [3]. This fact is significant because the eventual blind-years are greater when compared to adults, and so its incremental cost to healthcare systems. Incidence of blindness caused

\footnotetext{
* Correspondence: egraueh@gmail.com

${ }^{1}$ Cornea and Refractive Surgery Department, Institute of Ophthalmology

"Fundación de Asistencia Privada Conde de Valenciana", Mexico City, Mexico Full list of author information is available at the end of the article
}

by keratitis in children is 20 times higher in tropical developing countries with poor healthcare when compared to developed countries [4]. Ocular trauma, the main predisposing factor for infectious keratitis in children, is reported in $26-58.8 \%$ of cases [5].

Corneal infections in pediatric patients differ from adult disease in the risk factors, evolution, treatment compliance and complications. These differences usually result in a poorer visual prognosis $[2,6,7]$.

The purpose of this study is to describe the clinical, microbiological and predisposing factors of infectious keratitis in pediatric patients to improve the diagnosis, treatment and visual prognosis of this unique set of patients.

\section{Methods}

The study was approved by the ethics committee of the Institute of Ophthalmology "Conde de Valenciana", Mexico City. This is a retrospective review of clinical

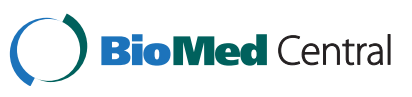


records of patients younger than 16 years with diagnosis of infectious keratitis seen at the Cornea and External Disease Unit at Institute of Ophthalmology "Conde de Valenciana", in Mexico City between January 2006 to December 2011. Microbiological data were obtained from the Department of Microbiology and Ocular Proteomics of the same institution.

The studied variables included demographic data, medical history, risk factors (history of ocular trauma, use of contact lenses, associated eye diseases, systemic diseases, previous ocular surgery), clinical presentation, initial and final visual acuity, medication use before and after diagnosis, and need for surgical therapy.

\section{Ophthalmic examination}

All patients had a detailed clinical evaluation followed by corneal scrapings. The material obtained on scraping was subjected to standard microbiology evaluation. Initial medical treatment was based on fourth-generation fluoroquinolones monotherapy and modified in accordance with clinical response, culture and antibiotic susceptibility results.

Every patient underwent a comprehensive ophthalmic examination, including but not limited to, presenting uncorrected distance visual acuity (UDVA) and pinhole corrected distance visual acuity (CDVA), slit-lamp biomicroscopy examination, fundoscopy and intraocular pressure. With respect to corrected visual acuity, patients were classified according to the revised ICD-10 [8]. The location, depth and size of the ulcer, as well as infiltrate appearance, presence or absence of lysis, hypopyon or neovascularization were documented at each visit. The longest diameter of the ulcer at presentation was defined as the size of the ulcer. The ulcer was defined, as being central if it involved the pupillary area otherwise it was recorded as peripheral. Follow-up was done as needed.

\section{Microbiology workup}

In all patients, corneal scrapings were obtained, smears were prepared for standard microbiologic evaluation including Gram and Giemsa stains. The sample was sowed in Columbia agar $+5 \%$ sheep, chocolate agar + PolyViteX (PVX) and Brain-Heart Infusion (BHI), those were incubated at $37^{\circ} \mathrm{C}$ and $5 \% \mathrm{CO}_{2}$; and Sabouraud dextrose agar, which was incubated at $28^{\circ} \mathrm{C}$ and $5 \% \mathrm{CO}_{2}$. The bacteria were identified using the Vitek 2 Compact system (bioMérieux, France) with GP-test Vitek card. The drug sensitivity was determined by the Kirby-Baüer method using the following antibiotic discs: polymyxin, oxacillin, neomycin, sulfamethoxazole, vancomycin, gentamicin, ciprofloxacin, ofloxacin, cephalothin, cephazolin and ceftazidime and according to Clinical and Laboratory Standards Institute guidelines [9]. Criteria for culture positivity were growth of the organism at the site of inoculation on two or more solid phase cultures, or growth at the site of inoculation on one solid phase media of an organism consistent with microscopy, or confluent growth on one media.

\section{Statistical evaluation}

The statistical analysis was performed with SPSS 17.0 software (SPSS Inc, Chicago, IL, USA). Descriptive statistics were obtained to determine the frequency and proportions. One-way analysis of variance (ANOVA) and linear regression model were used to evaluate the change of visual acuity from admission to discharge.

\section{Results}

\section{Patient characteristics}

Between 2006 and 2011, 41 corneal samples from 41 children with infectious keratitis were identified. Twentyone cases were male (51\%), and 20 were female (49\%). The mean patient age was 8.7 years \pm 5.1 (range, 3 months to 15 years). The mean time from the onset of symptoms to the ophthalmological examination was 12.7 days \pm 18.7 (range, $1-60$ days).

Predisposing factors were identified in $78 \%$ of cases, with 2 or more factors occurring in $26 \%$. The most common predisposing factor was ocular trauma (25\%), followed by wearing contact lenses and prolonged steroid treatment (Table 1). In cases associated with ocular trauma, pencils were the most common cause (10.6\%); other was associated with fireworks, cat scratch, rope, soil and toys.

Patients with CDVA $\geq 20 / 60$ at admission showed a statistically non-significant improvement of their vision at discharge, but happened inversely when CDVA was < $20 / 60(p=0.003$ ). A worsening of visual acuity was more pronounced when CDVA was less than 20/200 at admission (mean increment of logMar 1.04, $\mathrm{p}=0.002$ ). Linear regression analysis showed for lower visual acuity at

\section{Table 1 Predisposing factors for infectious keratitis in} children

\begin{tabular}{lcc}
\hline Predisposing factors & No. of patients & $\%$ \\
\hline Trauma & 8 & $25 \%$ \\
Contact lenses & 5 & $15.6 \%$ \\
Steroid treatment & 4 & $12.5 \%$ \\
Ocular rosacea & 3 & $9.4 \%$ \\
Previous ocular surgery & 3 & $9.4 \%$ \\
Systemic immunodeficiency & 3 & $9.4 \%$ \\
Congenital facial paralysis & 3 & $9.4 \%$ \\
Congenital anomalies of anterior chamber & 2 & $6.3 \%$ \\
Previous herpetic infection & 1 & $3.1 \%$ \\
\hline
\end{tabular}


admission, lower visual acuity at discharge $(\mathrm{p}<0.0001)$ [Figure 1].

The ophthalmological examination revealed a mean epithelial defect size of $2.74 \pm 1.6 \mathrm{~mm}$, with visual axis involvement in $63.2 \%$ of cases, anterior chamber reaction in $31.6 \%$ and hypopyon in $15.8 \%$.

\section{Treatment}

As mentioned previously initial medical therapy was based on fourth generation fluoroquinolones and modified according to clinical response or antibiogram. In 26 patients $(63.4 \%)$ this therapeutic regimen remained (0.5\% moxifloxacin or $0.3 \%$ gatifloxacin); 6 (14.6\%) were switched to macrolides (0.5\% erythromycin); 5 (12.2\%) to third generation cephalosporins (5\% ceftazidime); 3 (7.3\%) to third generation fluoroquinolones $(0.3 \%$ ciprofloxacin) and $1(2,4 \%)$ to topical $0.15 \%$ amphotericin B together with $1 \%$ natamycin and systemic oral itraconazole.

Medical therapy achieved remission in 39 cases (95\%). One case developed endophthalmitis and was successfully treated with intravitreal antibiotics (vancomycin and ceftazidime). Perforation occurred in a single case and was treated with tectonic keratoplasty.

\section{Microbiology}

Regarding the microbiological results, $66 \%(\mathrm{n}=27)$ were negative, $26 \%$ of them $(n=7)$ were previously treated with topical antibiotics. Cultures were positive in only $34 \%$ $(\mathrm{n}=14)$, which identified 7 different microorganisms and no polymicrobial infections. Bacteria were responsible for infection in 93\% (13) and fungi (Microsporum gypseum) in $7 \%(\mathrm{n}=1)$.

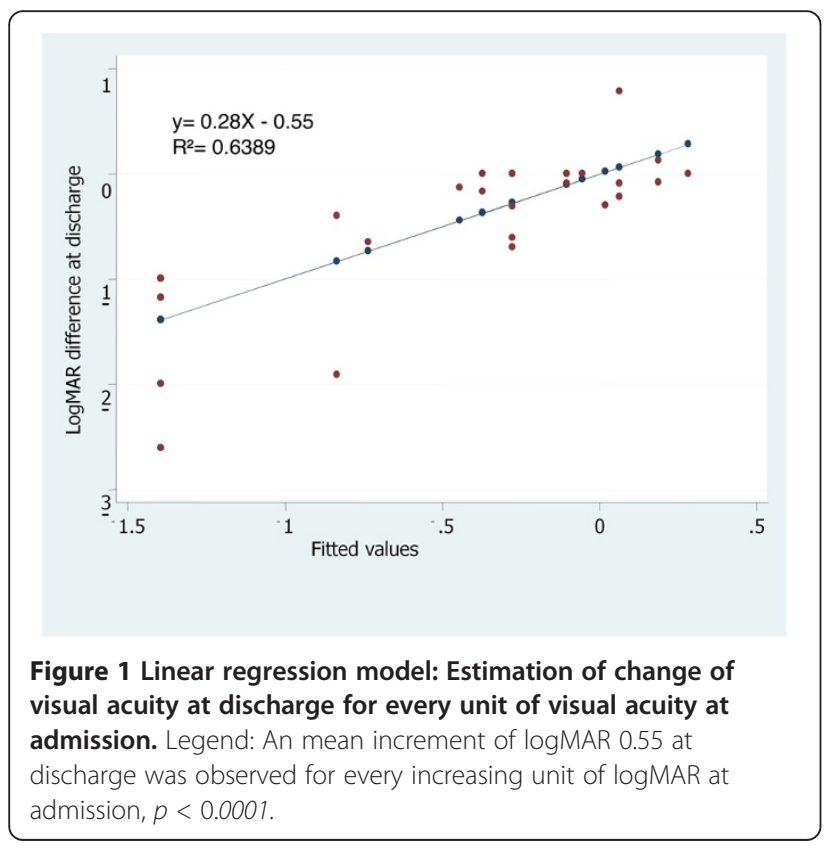

Gram-positive bacteria were isolated in $79 \%(n=11)$ of the positive cultures. Staphylococcus epidermidis was the most common isolate followed by equal frequencies of Streptococcus spp., Corynebacterium spp. and Pseudomonas aeruginosa. No significant association between risk factors and culture positivity was encountered (Table 2).

The antibiogram of Staphylococcus spp. isolates revealed that all isolates were sensitive to gentamicin, $80 \%$ $(n=4)$ were sensitive to vancomycin and ciprofloxacin. Eighty percent $(n=4)$ of these demonstrated resistance to sulfamethoxazole, and $75 \%(n=3)$ to cefazolin, oxacillin and polymyxin B. Eighty percent $(n=4)$ of these revealed resistance to multiple antibiotics.

All Streptococcus spp. isolates were sensitive to ciprofloxacin, cefazolin, ofloxacin and ceftriaxone, while $75 \%$ $(\mathrm{n}=3)$ were also sensitive to sulfamethoxazole, vancomycin and gentamicin. Seventy five percent $(n=3)$ were resistant to polymyxin $\mathrm{B}$.

Both Pseudomonas aeruginosa isolates were sensitive to gentamicin and resistant to ciprofloxacin and ceftazidime.

\section{Discussion}

Although uncommon, infectious keratitis in children is a condition that leads to an imminent risk of amblyopia and/or permanent visual loss and because of this the cost per case is very high [10].

Children may be poor historians and/or may not complain of ocular pain. Keratitis diagnosis and treatment may be delayed by parents, or by primary care physicians confusing keratitis with the less severe conjunctivitis, especially if the cornea is not severely affected and the infiltrate not macroscopically obvious. This may be reflected in our study where the mean time to diagnosis was almost 2 weeks. This fact may also explain the poor

Table 2 Microorganisms isolated from corneal ulcers in children

\begin{tabular}{lccc}
\hline Microorganisms & $\begin{array}{c}\text { No of positive } \\
\text { cultures }\end{array}$ & $\begin{array}{c}\% \text { of positive } \\
\text { cultures }\end{array}$ \\
\hline $\begin{array}{l}\text { Gram-positive } \\
\text { bacteria }\end{array}$ & $\begin{array}{c}\text { Staphylococcus } \\
\text { epidermidis } \\
\text { Staphylococcus } \\
\text { aureus } \\
\text { Streptococcus } \\
\text { viridans }\end{array}$ & 4 & $28.6 \%$ \\
& $\begin{array}{c}\text { Streptococcus } \\
\text { pneumoniae }\end{array}$ & 2 & $7.1 \%$ \\
Gram-negative & $\begin{array}{c}\text { Corynebacterium sp. } \\
\text { Pseudomonas } \\
\text { bacteria }\end{array}$ & 2 & $14.3 \%$ \\
Fungi & $\begin{array}{c}\text { Microsporum } \\
\text { gypseum }\end{array}$ & 1 & $14.3 \%$ \\
No growth & 2 & 27 & $14.3 \%$ \\
\hline
\end{tabular}


visual outcomes and highlights the importance to educate parents and primary care personnel in the importance of immediate referral whenever the cornea may be involved.

In our series, a history of trauma was the major predisposing factor, present in approximately one quarter of the cases (25\%). This result is consistent with multiple microbial keratitis studies involving children where ocular trauma has been associated in up to two thirds of the cases. (26-58.8\%) [2,11-13]. Corneal trauma disrupts the protective mechanism of the corneal epithelium, facilitating bacterial adhesion and accelerating penetration and replication of microorganisms [12,13]. Children are less careful than adults and do not understand the harm that is associated with dangerous objects. Plants, metals, plastic parts, fireworks and pencils may cause ocular trauma [2].

In our study, $15.6 \%$ of patients had a history of wearing contact lenses. Interactions between contact lens and ocular surface generated by chronic or improper contact lens wear such as overnight wear, may produce epithelial defects that predispose the wearer to bacterial adhesion $[14,15]$. Exposure to contaminated disinfectant solutions and biofilm formation are additional mechanisms that can cause corneal infection $[16,17]$. Although statistics are lacking, pediatric contact lens wear may be more common in populations where high myopia is prevalent and/or orthokeratology is popular. In our population, orthokeratology is rarely used and but its use should be cautiously advised specially in children with other risk factors for infections (pediatric rosacea, recurrent blepharitis) $[6,18]$.

The influence of systemic diseases and malnutrition on the wound healing process should be considered as a predisposing factor for microbial keratitis in children $[19,20]$. A wide variety of factors such as low socioeconomic status, incomplete immunization profile and systemic diseases, including hypoxic encephalopathy, pulmonary stenosis, protein-energy malnutrition, multiple congenital anomalies and prematurity have been associated with severe microbial keratitis in children $[2,12,13,21,22]$. Jhanji and co-authors recently reviewed the role of immunization and malnutrition in corneal ulcers in children 5 years or younger [22]. The severity of protein-energy malnutrition was related significantly to the occurrence of bilateral infection, to an incomplete immunization scheme and poor socioeconomic status, however this study did not address the confounding between these variables. In our study, we found 3 cases with associated systemic diseases. Two children had psychomotor retardation and malnutrition, and the other had chronic cardiopulmonary disease.

Local predisposing factors for infectious keratitis were found in 16 cases (50\%), which included chronic steroid use, ocular rosacea and previous ocular surgeries, congenital facial paralysis and previous herpetic infection. These factors, as well as dry eye, exposure keratopathy and eyelid abnormalities act as facilitators of corneal infection $[11,13]$.

Regarding microbiological profile, we found that cultures were positive in $34 \%$ of cases, a value that was lower than those reported in other studies ( $48 \%$ to $87 \%$ ) $[20,21,23]$. Self-prescribed antibiotic, microorganisms with slow growth on culture media, viral causes of keratitis, improper corneal sampling, and the inherent difficulty in getting corneal samples from pediatric patients may account for the low positivity rate observed in our study. The higher rates of culture positivity reported in the other studies, may also be explained by their use of general anesthesia or deep sedation for corneal scrapings in uncooperative patients $[20,21,23]$.

As shown previously by other authors, Gram-positive microorganisms are the main etiological agents of infectious keratitis in children [2,7]. Over the years, an increased incidence of keratitis caused by coagulasenegative Staphylococcus has been reported, [12,13,20-23] and many studies consider coagulase-negative Staphylococcus as an important cause of endophthalmitis [24-26]. The antibiotic susceptibility of coagulase-negative Staphylococcus isolates is unpredictable, and that multiresistance to antibiotics is common. Therefore, an antibiogram should be performed in the clinically significant ocular infections that arise from these organisms [24].

We observed a high resistance of Staphylococcus spp. to the antibiotics known for their action against grampositive organisms, including sulfamethoxazole, firstgeneration cephalosporins and oxacillin; the latter used as a surrogate marker for methicillin-resistant organisms. A hundred percent of these cases were susceptible to gentamicin, and $80 \%$ to ciprofloxacin and vancomycin. Alternatively; Streptococcus spp. isolates were sensitive to the majority of antibiotics. Resistance to multiple antibiotics was seen in $80 \%$ of Staphylococcus spp. and in 25\% of Streptococcus spp. isolates. Prolonged antibiotic therapy is known to promote the adaptation of organisms and development of specific cross-resistance mechanisms although knowledge of the local resistance trends in ophthalmic specimens is mandatory to provide a prompt and effective treatment $[27,28]$.

In general, fluoroquinolones susceptibility profile was good across our series of positive cultures, making this class of antibiotic suitable for empiric treatment that may be modified according to the antibiogram results. Although in our setting resistance is uncommon, sites where it's use is widespread in healthcare, resistance is a concern $[29,30]$.

Finally, as previously reported [31], vancomycin is an effective anti-staphylococcal drug that is rarely associated 
with resistance, hence, it is important that this drug be reserved for treating infections that are resistant to other anti-staphylococcal antibiotics or in cases of severe corneal infections. In this report we encountered a Staphylococcus epidermidis strain that was resistant to vancomycin, which suggests the existence of some strains with complex resistance mechanisms in our environment.

The findings of this study should be interpreted cautiously. This study is limited by its small sample size and is subject to selection bias since it was performed at a tertiary referral eye care center, so the results here presented cannot be extrapolated to the general population. Nevertheless, our results strengthen the body of knowledge around infectious keratitis in children and contribute to a better understanding of microbial corneal ulcers in the pediatric patient, in the hope of improving their visual outcome.

\section{Conclusion}

In conclusion, trauma and contact lenses were the main predisposing factors for infectious keratitis in patients 16 years or younger. The frequent involvement of the central cornea, the delay in reaching specialty care and low positivity of cultures may all account for the poor visual outcomes conveyed in our study.

\section{Competing interests}

The authors declare that they have no competing interests.

\section{Authors' contributions}

PCS, VMBL, EOGH conceived, designed and drafted the manuscript. LVG, MOC, NLLE, CGJ, LABH performed the data collection. JCHC, ANP, ARM contributed to review and to the revision of the manuscript. All authors read and approved the final manuscript.

\section{Acknowledgments}

The authors would like to thank Dr Mark Mannis, for his support and the "Fundación de Asistencia Privada Conde de Valenciana" Ophthalmology Institute.

\section{Author details}

${ }^{1}$ Cornea and Refractive Surgery Department, Institute of Ophthalmology "Fundación de Asistencia Privada Conde de Valenciana", Mexico City, Mexico. ${ }^{2}$ Microbiology and Ocular Proteomics, Research Unit, Institute of Ophthalmology "Fundación de Asistencia Privada Conde de Valenciana", Mexico City, Mexico.

Received: 12 January 2013 Accepted: 6 October 2013

Published: 16 October 2013

\section{References}

1. Whitcher JP, Srinivasan M: Cornel ulceration in the developing world a silent epidemic. Br J Ophthalmol 1997, 8:622-631.

2. Parmar P, Salman A, Kalavathy CM, Kaliamurthy J, Thomas PA, Jesudasan CA: Microbial keratitis at extremes of age. Cornea 2006, 25(2):153-158.

3. Underwood BA: Update: xerophthalmia, keratomalacia, and child mortality including measles. In World Blindness and Its Prevention. Volume 4. Edited by Kupfur C, Gillen T. Oxford: Oxford University Press; 1990:171-175.

4. Maurin JF, Renard JP, Ahmedou O, Bidaux F, Dordain Y, Pariselle J, Froussart F, Dot C, Rigal-Sastourne JC: [Corneal blindness in tropical areas]. Med Trop (Mars) 1995, 55(4 Pt 2):445-449.
5. Ormerod LD, Murphree AL, Gomez DS, Schanzlin DJ, Smith RE: Microbial keratitis in children. Ophthalmology 1986, 93(4):449-455.

6. Young AL, Leung AT, Cheng LL, Law RW, Wong AK, Lam DS: Orthokeratology lens-related corneal ulcers in children: a case series. Ophthalmology 2004, 111(3):590-595.

7. Satpathy G, Vishalakshi P: Ulcerative keratitis: Microbial profile and sensitivity pattern: A five year study. Ann Ophthalmol 1995, 27(5):301-306.

8. Dandona L, Dandona R: Revision of visual impairment definitions in the International Statistical Classification of Diseases. BMC Med 2006, 16:4-7.

9. Clinical and Laboratory Standards Institute: Performance standards for antimicrobial susceptibility testing: Seventeenth informational supplement. CLSI document M100-S17. 940 West Valley Road, Suite 1400, Wayne, Pennsylvania: Clinical and Laboratory Standards Institute; 2007:19087-1898. ISBN 1-56238-625-5.

10. Carlton J, Karnon J, Czoski-Murray C, Smith KJ, Marr J: The clinical effectiveness and cost-effectiveness of screening programmes for amblyopia and strabismus in children up to the age of 4-5 years: a systematic review and economic evaluation. Health Technol Asess 2008, 12(25):194. iii, xi.

11. Cruz OA, Sabir SM, Capo H, Alfonso EC: Microbial keratitis in childhood. Ophthalmology 1993, 100:192-196.

12. Al Otaibi AG, Allam K, Damri AJ, Shamri AA, Kalantan H, Mousa A: Childhood microbial keratitis. Oman J Ophthalmol 2012, 5(1):28-31.

13. Song $X, X u$ L, Sun $S$, Zhao J, Xie L: Pediatric microbial keratitis: a tertiary hospital study. Eur J Ophthalmol 2012, 22(2):136-141.

14. Dart JK, Radford CF, Minassian D, Verma S, Stapleton F: Risk factors for microbial keratitis with contemporary contact lenses: a case-control study. Ophthalmology 2008, 115(10):1647-1654.

15. Stapleton F, Keay L, Edwards K, Naduvilath T, Dart JK, Brian G, Holden BA The incidence of contact lens-related microbial keratitis in Australia. Ophthalmology 2008, 115(10):1655-1662.

16. Behlau I, Gilmore MS: Microbial biofilms in ophthalmology and infectious disease. Arch Ophthalmol 2008, 126(11):1572-1581.

17. Shovlin JP, Argüeso P, Carnt N, Chalmers RL, Efron N, Fleiszig SM, Nichols JJ, Polse KA, Stapleton F, Wiley L, Willcox M, Bright FV, Efron N, Jones LW, Keir N, Peterson RC, Stapleton F: 3. Ocular surface health with contact lens wear. Cont Lens Anterior Eye 2013, 36(1):14-21.

18. Watt K, Swarbrick HA: Microbial keratitis in overnight orthokeratology: review of the first 50 cases. Eye Contact Lens 2005, 31(5):201-208.

19. Wong WY, Lai TYY, Chi SCC, Lam DSC: Pediatric ocular surface infections: a 5-year review of demographics, clinical features, risk factors, microbiological results, and treatment. Cornea 2011, 30:995-1002.

20. Emery PW, Sanderson P: The effects of dietary restriction on protein synthesis and wound healing after surgery in the rat. Clin Sci 1995, 89(4):383-388.

21. Kunimoto DY, Sharma S, Reddy MK, Gopinathan U, Jyothi J, Miller D, Rao GN: Microbial keratitis in children. Ophthalmology 1998, 105(2):252-257.

22. Vajpayee RB, Ray M, Panda A, Sharma N, Taylor HR, Murthy GV, Satpathy G, Pandey RM: Risk factors for pediatric presumed microbial keratitis: a case-control study. Cornea 1999, 18(5):565-569.

23. Jhanji $V$, Naithani $P$, Lamoureux E, Agarwal $T$, Sharma $N$, Vajpayee RB: Immunization and nutritional profile of cases with atraumatic microbial keratitis in preschool age group. Am J Ophthalmol 2011, 151(6):1035-1040

24. Singh G, Palanisamy M, Madhavan B, Rajaraman R, Narendran K, Kour A, Venkatapathy N: Multivariate analysis of childhood microbial keratitis in South India. Ann Acad Med Singapore 2006, 35(3):185-189.

25. Pinna A, Zanetti S, Sotgiu M, Sechi LA, Fadda G, Carta F: Identification and antibiotic susceptibility of coagulase negative staphylococci isolated in corneal/external infections. Br J Ophthalmol 1999, 83(7):771-773.

26. Kattan HM, Flynn HW Jr, Pflugfelder SC, Robertson C, Forster RK: Nosocomial endophthalmitis survey. Current incidence of infection after intraocular surgery. Ophthalmology 1991, 98(2):227-238.

27. Speaker MG, Milch FA, Shah MK, Eisner W, Kreiswirth BN: Role of external bacterial flora in the pathogenesis of acute postoperative endophthalmitis. Ophthalmology 1991, 98(5):639-649. discussion 650.

28. Asbell PA, Colby KA, Deng S, McDonnell P. Meisler DM, Raizman MB, Sheppard JD Jr, Sahm DF: Ocular TRUST: nationwide antimicrobial susceptibility patterns in ocular isolates. Am J Ophthalmol 2008, 145(6):951-958. 
29. Chalita MR, Hofling-Lima AL, Paranhos A Jr, Schor P, Belfort R Jr: Shifting trends in in vitro antibiotic susceptibilities for common ocular isolates during a period of 15 years. Am J Ophthalmol 2004, 137(1):43-51.

30. Graves A, Henry M, O'Brien TP, Hwang DG, Van Buskirk A, Trousdale MD: In vitro susceptibilities of bacterial ocular isolates to fluoroquinolones. Cornea 2001, 20(3):301-305.

31. Guzmán Lista MDC, Lozada Oca RA: Detección de Staphylococcus aureus meticilino-resistentes aislados de pacientes con infecciones nosocomiales y adquiridas en la comunidad. Rev Soc Ven Microbiol 2007, 27:349-363.

doi:10.1186/1471-2415-13-54

Cite this article as: Chirinos-Saldaña et al:: Clinical and microbiological profile of infectious keratitis in children. BMC Ophthalmology 2013 13:54.

\section{Submit your next manuscript to BioMed Central and take full advantage of:}

- Convenient online submission

- Thorough peer review

- No space constraints or color figure charges

- Immediate publication on acceptance

- Inclusion in PubMed, CAS, Scopus and Google Scholar

- Research which is freely available for redistribution 